\title{
Relationship between Dental Anxiety, Self-assessed Dental Status, and DMFT among Patients in a Tertiary Health Care Center at Pune: A Cross-sectional Study
}

\author{
T Prasanth ${ }^{1}$, MS Rana ${ }^{2}$
}

\begin{abstract}
Aim and objective: To measure dental anxiety and to evaluate the relationship between dental anxiety, self-assessed dental status, and decayed, missing, and filled teeth (DMFT) scores.

Materials and methods: Male patients in the age group of 18-55 years were randomly selected amongst those attending the outpatient department (OPD) at a tertiary health care center in Pune. A questionnaire was used to collect the data, which included self-assessment of dental status as well as the Modified Dental Anxiety Scale (MDAS). Dental caries status was evaluated using the World Health Organization (WHO) caries diagnostic criteria for DMFT.

Results: Slightly more than half of the participants assessed their dental status as good, $47.6 \%$ as fair, and $1.2 \%$ as bad. Approximately $50 \%$ of the participants reported not anxious, $21.2 \%$ as moderately anxious, $20.8 \%$ as highly anxious, and $6.8 \%$ as extremely anxious. The mean MDAS score was $11.23 \pm 4.17$ amongst the participants. The study showed a significant relationship between dental anxiety, self-assessed dental status, and high DMFT scores $(p<0.05)$.

Conclusion: The present study strongly suggests that in younger people, dental anxiety is associated with a host of preventive behavior problems as well as poor dental health.

Clinical significance: Dental anxiety is widely prevalent in the general population and can lead to variable avoidance behavior toward dental treatment.

Keywords: Cross-sectional study, Decayed, missing, and filled teeth, Dental anxiety, Self-assessed dental status.

Journal of Oral Health and Community Dentistry (2020): 10.5005/jp-journals-10062-0076
\end{abstract}

\section{INTRODUCTION}

Anxiety is an emotion that is distressing and may have no specific cause. It produces the same physiological response as fear leading to an increase in sympathetic activity in the autonomic nervous system, which may remain constant if the source is not identified and removed. Dental anxiety is common with about $6-15 \%$ of the world population suffering from it consequently leading to dental treatment avoidance. ${ }^{1}$

Anxiety about dental treatment and fear remain widespread, despite technological advances, such as better anesthesia and treatment techniques. It is believed that dental anxiety operates through behavioral mechanisms (e.g., avoidance of dental treatment), which has a detrimental effect on oral health. Several studies have shown that patients seeking treatment in dental fear clinics generally have poorer dental health than other patients. ${ }^{2-4}$

One of the most widely used instruments for measuring dental anxiety is Corah's Dental Anxiety Scale (DAS). ${ }^{5,6}$ It was developed to assess the tendency to appraise dental treatment situations as dangerous and threatening which was modified later to Modified Corah's Dental Anxiety Scale (MDAS) by the addition of a question related to anesthetic injection in the DAS. ${ }^{7}$ Dental caries is one of the most prevalent chronic pathologies affecting mankind, hugely impacting the quality of life. The WHO caries diagnostic criteria for decayed, missing, and filled teeth (DMFT) are the simplest and most commonly used in epidemiologic surveys of dental caries. ${ }^{8}$

The aim of this study was to measure dental anxiety and to evaluate the relationship between self-assessed dental status, dental anxiety, and DMFT scores.
${ }^{1}$ Department of Periodontology, AFMC, Pune, Maharashtra, India

${ }^{2}$ Public Health Dentistry, Ludhiana, Punjab, India

Corresponding Author: MS Rana, Public Health Dentistry, Ludhiana, Punjab, India, Phone: +91 9819365449, e-mail: msrdent@gmail.com

How to cite this article: Prasanth T, Rana MS. Relationship between Dental Anxiety, Self-assessed Dental Status, and DMFT among Patients in a Tertiary Health Care Center at Pune: A Cross-sectional Study. J Oral Health Comm Dent 2020;14(3):75-77.

Source of support: Nil

Conflict of interest: None

\section{Materials and Methods}

A cross-sectional, questionnaire-based study was conducted to find the association between self-assessed oral health status, DMFT, and dental anxiety amongst male patients aged 18-55 years visiting OPD at a tertiary health care center in Pune for treatment from Nov. 10, 2019, to Jan. 10, 2020.

Voluntary written informed consent was taken from the selected patients. The purpose of the study was clearly explained to them before obtaining their consent.

A sample size of 500 participants was estimated from the pilot study for a confidence level of $95 \%$ and a design effect of 0.65 . Uncooperative, medically and physically compromised, and those under psychiatric treatment were excluded from the study.

A self-administered close-ended questionnaire was used to collect the data. A pilot study was done to check for the validity and

(0) The Author(s). 2020 Open Access This article is distributed under the terms of the Creative Commons Attribution 4.0 International License (https:// creativecommons.org/licenses/by-nc/4.0/), which permits unrestricted use, distribution, and non-commercial reproduction in any medium, provided you give appropriate credit to the original author(s) and the source, provide a link to the Creative Commons license, and indicate if changes were made. The Creative Commons Public Domain Dedication waiver (http://creativecommons.org/publicdomain/zero/1.0/) applies to the data made available in this article, unless otherwise stated. 
reliability of the questions and required modifications were done accordingly. The questionnaire was both in English and in Marathi (local language). The translation was done by a bilingual translator. It was translated back to English to check for validity.

The structured questionnaire consisted of three main parts: patients' demographic profile, patient's history and self-assessment of dental status, and finally, questions to measure dental anxiety using the MDAS. The questionnaire was filled by the patients themselves while waiting for their turn in the waiting room. The English version of MDAS was used as it has good reliability and validity amongst the Indian population. It is a brief, five-item instrument with a five-point Likert response for each question which summed together to produce a total score ranging from 5 to $25 .{ }^{9}$

The case definition of dentally anxious individual and severity of dental anxiety was determined by converting interpretation of Corah's DAS to the MDAS scale using the formula $0.56+(1.15 \times$ DAS $) .{ }^{10}$ The interpretation of the MDAS scale based on this conversion is given in Table 1.

Examination and recording were done by the same person. Oral examination was carried out after the patients returned the questionnaire to record the DMFT. The WHO caries diagnostic criteria for DMFT were used to evaluate dental caries status (Tables 2 to 5).

Table 1: Interpretation of modified dental anxiety scale

\begin{tabular}{ll}
\hline Anxiety score & Interpretation \\
\hline$<11$ & Not anxious \\
$11-14$ & Moderately anxious \\
$15-18$ & Highly anxious \\
$>19$ & Extremely anxious \\
\hline
\end{tabular}

Table 2: Age-wise distribution of study subjects

\begin{tabular}{lc}
\hline Age group (in years) & Total patients $n(\%)$ \\
\hline $18-25$ & $168(33.6)$ \\
$26-35$ & $212(42.4)$ \\
$36-45$ & $70(14)$ \\
$46-55$ & $50(10)$ \\
Total & $500(100)$ \\
\hline
\end{tabular}

Table 3: Distribution of study population based on dental anxiety levels

\begin{tabular}{lc}
\hline Dental anxiety levels & Patients $n(\%)$ \\
\hline Not anxious & $256(51.2)$ \\
Moderately anxious & $106(21.2)$ \\
Highly anxious & $104(20.8)$ \\
Extremely anxious & $34(6.8)$ \\
\hline
\end{tabular}

Table 4: Distribution of the study subjects according to the dental anxiety score and self-assessed dental status

\begin{tabular}{lccl}
\hline & \multicolumn{3}{c}{ Self-assessed dental status } \\
\cline { 2 - 4 } Dental anxiety & Good & Fair & Poor \\
\hline Not anxious & 28.4 & 22.8 & 0 \\
Moderately anxious & 5.6 & 14.4 & 1.2 \\
Highly anxious & 12 & 8.8 & 0 \\
Extremely anxious & 5.2 & 1.6 & 0 \\
\hline
\end{tabular}
$p=0.00$
Data were collected and analyzed by SPSS 20.0 using descriptive statistics. Chi-square and Pearson's correlation test was done to assess the association and correlation between dental anxiety and self-assessed oral health status and dental anxiety and DMFT. Results were considered significant at the $5 \%$ significance level $(p<0.05)$.

\section{Results}

The present cross-sectional, questionnaire-based study was conducted to find the association between self-assessed oral health status and dental anxiety.

Among our study population, $51.2 \%$ of patients assessed their dental status as good, $47.6 \%$ as fair, and $1.2 \%$ as bad, respectively. The prevalence of dental anxiety was $48.8 \%$ and the mean MDAS was $11.23 \pm 4.17$ amongst the patients.

In this study, a negative correlation was found between dental anxiety and self-assessed dental status which was statistically not significant, but there was a significant positive correlation between dental anxiety and DMFT score (Table 6).

\section{Discussion}

Dental anxiety is a potential barrier to seek dental treatment and its relation to oral health is important. Poorer dental health may result from avoidance of dental care due to anxiety about visiting the dentist. Some individuals also get anxious as they feel that considerable dental treatment is required.

This study was conducted with a sample of 500 male participants in the age group of 18-55 years. In this study, dental anxiety was found to be greatest in the age group of 26 to 35 years.

About one in two (51.2\%) of the patients in this study assessed their dental status as good and $1.2 \%$ as poor whereas in a study conducted to determine the factors associated with dental anxiety, $70.2 \%$ of the study subjects assessed it as good and $5 \%$ as poor. ${ }^{11}$ In another study conducted to investigate factors associated with regular dental visits in an adult population self-perceived oral health status was good to excellent in $68.8 \%$ of the population whereas it was $31.4 \%$ for fair to poor. ${ }^{12}$

Table 5: Distribution of the study subjects according to dental anxiety and decayed, missing, and filled teeth (DMFT) scores

\begin{tabular}{lclll}
\hline & \multicolumn{4}{c}{ DMFT } \\
\cline { 2 - 5 } Dental anxiety & $0-3 N(\%)$ & $4-7 N(\%)$ & $8-11 N(\%)$ & $\geq 12 N(\%)$ \\
\hline Not anxious & $128(25.6)$ & $90(18)$ & $20(4.0)$ & $18(3.6)$ \\
$\begin{array}{l}\text { Moderately } \\
\quad \text { anxious }\end{array}$ & $32(6.4)$ & $64(12.8)$ & $10(2.0)$ & $0(0)$ \\
Highly anxious & $38(7.6)$ & $50(10)$ & $10(2.0)$ & $6(1.2)$ \\
Extremely anxious & $8(1.6)$ & $10(2)$ & $6(1.2)$ & $10(2)$ \\
\hline
\end{tabular}

Table 6: Correlation between self-assessed dental status, decayed, missing, and filled teeth (DMFT), and dental anxiety

\begin{tabular}{lll}
\hline & Dental anxiety & $p$-value \\
\hline Dental status & -0.010 & 0.820 \\
DMFT & $0.247^{*}$ & 0.000 \\
\hline${ }^{*} p<0.05$ & &
\end{tabular}


As expected, a significant negative correlation was found between self-assessed dental status and dental anxiety.

In the present study, the mean dental anxiety score for patients was $11.23+4.17$ in $48.8 \%$ of the patients. Dental anxiety has been associated with poor oral health status, as measured clinically and by self-assessment. DMFT of 4-7 was observed in about $20 \%$ of the patients.

A high DMFT was associated with moderate dental anxiety, and a positive but significant weak correlation was found between the DMFT score and dental anxiety. Even in the subgroup with high dental anxiety, several subjects reported visiting the dentist during the last one or two years. The high anxiety group also had the largest number of fillings, indicating that much restorative work had been performed. It can be argued that the high-anxiety group received more treatment at each visit and that this might be a variable related to the accessibility of services. However, there is no reason to believe that there are differences regarding the accessibility of services for high and low anxiety patients, as in this tertiary care institute, usually there is easy accessibility of dental services.

\section{Conclusion}

The present study suggests strongly that in younger people, dental anxiety is associated with a host of preventive behavior problems as well as poor dental health. Substantial proportions of patients with dental anxiety undergo dental treatment but are quite fearful while getting the treatment. In dental practice, possible preventive problems should also be addressed to prevent negative dental health progression, which can further aggravate treatment-induced anxiety reactions.

In this study, the participants consisted of males only, thus no gender differences could be found. It would be interesting to conduct a similar study for females and compare the results.

Our findings showed that the use of patient self-assessment was a good predictor of patient dental status. The information presented in this study could serve as a tool for public and preventive dentistry, as well as to help the dental practitioner in managing patients according to their complaints and selfassessment. Dental practitioners could ask patients to assess their dental status prior to treatment or appointment. This will help the practitioner to accomplish more effective time and patient management. Furthermore, the use of patient self-assessment should be a part of dental training. Students should be urged to ask questions to their patients regarding their dental status during the first interview.

\section{Clinical Significance}

Dental anxiety is widely prevalent in the general population and can lead to variable avoidance behavior toward dental treatment. The clinician should identify and allay their fear and anxiety for better patient management.

\section{References}

1. Samorodnitzky GR, Levin L. Self-assessed dental status, oral behavior, DMF, and dental anxiety. J Dent Educ 2005;69(12):1385-1389. DOI: 10.1002/j.0022-0337.2005.69.12.tb04038.x.

2. Hakeber M, Berggren U, Grondahl H-G. A radiographic study of dental health in adult patients with dental anxiety. Community Dent Oral Epidemiol 1993;21:27-30. DOI: 10.1111/j.1600-0528.1993.tb00714.x.

3. Berggren U, Linde A. Dental fear and avoidance: a comparison of two modes of treatment. J Dent Res 1984;63:1223-1228. DOI: $10.1177 / 00220345840630101201$.

4. Berggren U, Meynert G. Dental fear and avoidance: causes, symptoms, and consequences. J Am Dent Assoc 1984;109:247-251. DOI: 10.14219/ jada.archive.1984.0328.

5. Corah NL. Development of a dental anxiety scale. J Dent Res 1969;48:596. DOI: 10.1177/00220345690480041801.

6. Corah NL, Gale EN, Illig SJ. Assessment of a dental anxiety scale. J Am Dent Assoc 1978;97:816-819. DOI: 10.14219/jada.archive.1978.0394.

7. Humphris GM, Dyer TA, Robinson PG. The modified dental anxiety scale: UK general public population norms in 2008 with further psychometrics and effects of age. BMC Oral Health 2009;9:20. DOI: 10.1186/1472-6831-9-20.

8. World Health Organization. Dentition status and treatment needs. In: Oral Health Surveys: Basic Methods, 4th ed. Geneva: World Health Organization; 1997. pp. 40-47.

9. Acharya S. Factors affecting dental anxiety and beliefs in an Indian Population. J Oral Rehabil 2008 Apr;35(4):259-267. DOI: 10.1111/j.13652842.2007.01777.x.

10. Freeman R, Clarke HMM, Humphris GM. Conversion tables for the Corah and modified dental anxiety scale. Community Dent Health 2007;24:49-54.

11. Doerr PA, Lang WP, Nyquist LV, et al. Factors associated with dental anxiety. J Am Dent Assoc 1998;129:1111-1119. DOI: 10.14219/jada. archive.1998.0386.

12. Sohn W, Ismail AI. Regular dental visits and dental anxiety in an adult dentate population. J Am Dent Assoc 2005;136(1):58-66. DOI: 10.14219/jada.archive.2005.0027. 